\title{
1976-2006. Del periodismo de investigación al ciberperiodismo crítico en México. Del semanario Proceso a Reporte Índigo
}

\author{
Octavio Islas (Universidad Autónoma de México, México) \\ Amaya Arribas (Tecnológico de Monterrey, México) \\ Recibido 16/6/2007 \\ Aprobado 20/7/2007
}

ResUMEN: Para no pocas generaciones el semanario Proceso ha representado el único medio informativo cuyo contenido suelen pasar por alto la mayoría de los medios de comunicación en México, no acostumbrados a realizar un riguroso periodismo crítico. En años recientes el tránsito a la economía del conocimiento ha impuesto grandes cambios en los medios de comunicación. Hoy resulta indispensable también emplear internet. Reporte Índigo se ubica entre el reducido número de medios informativos incubados desde el imaginario mismo de la web que, efectivamente, comprenden el significado de la tesis "el medio es el mensaje".

Palabras clave: Periodismo - ciberperiodismo - periodismo independiente en el México contemporáneo

1976-2006. From research journalism to critic cyber journalism in Mexico. From the weekly magazine Proceso to the Reporte Índigo.

SUMMARY: For not few generations Proceso has been the only mean to get information better than the one in Mexico's normal media offers, which almost never has the kind of hard critical journalism. In recents years, the shift to knowledge economy has imposed great changes in the overall media. Today, the use of the internet is now mandatory. Reporte Indigo is placed among a reduced number of media, born inside the web, that understand thesis "the medium is the message".

Key words: Journalism - cyber journalism - independent journalism in today's Mexico. 
E ntre el sábado 6 de noviembre de 1976 y el viernes 27 de octubre de 2006, transcurrieron 29 años y 355 días.

Excélsior es el segundo periódico en antigüedad entre los diarios que aún se publican en la Ciudad de México. El decano entre los periódicos que circulan en la capital es El Universal, fundado por Félix Fulgencio Palavicini, y cuyo primer ejemplar fue distribuido el primero de octubre de 1916. Excélsior fue fundado por Rafael Alducin y su primer ejemplar salió a la venta el 18 de marzo de 1917. En 1938, Excélsior fue transformado en cooperativa.

Julio Scherer García ingresó a Excélsior a los 18 años de edad. Inicialmente se desempeñó como "mandadero". Gracias a su incuestionable talento y dedicación, Scherer fue elegido director general de Excélsior el 31 de agosto de 1968. De acuerdo con Carlos Monsiváis, con la llegada de Scherer a la dirección de Excélsior se iniciaron profundos cambios en el diario:

En 1968 el grupo de Julio Scherer gana la dirección de Excélsior y casi su primer acto es suprimir la venta de las ocho columnas, tan increíble como pueda parecer (insisto: júzguese al periodismo no con los criterios actuales, sino con los de una sociedad sometida por entero al Presidente y al PRI). Con la mayor rapidez posible, Scherer transforma las reglas de juego y estimula la información confiable. No desaparecen de golpe los periodistas corruptos, o se interrumpe la cercanía entre prensa y poder; tan sólo, y esta transformación es inusitada, se ejerce el periodismo con rigor creciente, y en un medio sometido a todas las asfixias, se inicia el reportaje de investigación. ${ }^{1}$

Julio Scherer García asumió la dirección de Excélsior en un momento de particular intensidad en la historia del México contemporáneo: 1968. De acuerdo con Octavio Paz, 1968 admite ser considerado como "año axial":

1968 fue un año axial: protestas, tumultos y motines en Praga, Chicago, París, Tokio, Belgrado, Roma, México, Santiago... De la misma manera que las epidemias medievales no respetaban ni las fronteras religiosas ni las jerarquías sociales, la rebelión juvenil anuló las clasificaciones ideológicas. A esta espontánea universalidad de la protesta correspondió una reacción no menos espontánea y universal: invariablemente los gobiernos atribuyeron los desórdenes a una conspiración del exterior. $^{2}$

1 MONSIVÁIS, Carlos "Adiós a las concesiones". Proceso. Edición del aniversario 30, octubre-diciembre del 2006, p. 201.

2 PAZ, Octavio. Posdata, 1987, pp. 21-22. 
En 1968 el movimiento popular estudiantil exhibió el avanzado estado de descomposición que presentaba el sistema político mexicano. En México, el saldo del llamado "año axial" fue sumamente doloroso. El 2 de octubre de 1968, centenares de estudiantes perdieron la vida en la Plaza de las Tres Culturas, en Tlatelolco. Esa tarde el Consejo Nacional de Huelga $(\mathrm{CNH})$ celebraba un mitin en ese lugar. En Días de guardar, Carlos Monsiváis refiere:

Era la tarde del mitin. Faltaban diez días para que diesen principio los XIX Juegos Olímpicos y fuese notificado el planeta entero de cuánto habíamos progresado desde que Cuauhtémoc arrojó la primera flecha. Y eran las cinco y media y la gente se agrupaba, absorta en la fatiga de quien presiente la transferencia que lo convertirá en el asistente del próximo mitin, y estaban los Comités de Lucha con sus pancartas y los brigadistas y los padres y madres de familia seguros de la calidad de su apoyo, y había simpatizantes de clase media y empleados o profesionistas arraigados en la justicia del Movimiento Estudiantil y periodistas nacionales y reporteros de todo el mundo (...). Y eran las seis y diez de la tarde y de pronto, mientras el equipo de sonido divulgaba otra exhortación, rayó el cielo el fenómeno verde emitido por un helicóptero, el efluvio verde, la señal verde de una luz de bengala "desde la niebla de los escudos", desde el reposo de lo inesperado. Y se oyeron los primeros tiros y alguien cayó en el tercer piso del Edificio Chihuahua y todos allí se arrojaron al suelo y brotaron hombres con la mano vendada o el guante blanco y la exclamación “iBatallón Olimpia!”, y el gesto era iracundo, frenético, como detenido en los confines del resentimiento, como hipnótico, gesto que se descargaba una y mil veces, necedad óptica, engendro de la claridad solar desaparecida, descomposición del instante en siglos alternados de horror y crueldad (...). Y los tanques entraron a la Plaza y venían los soldados a bayoneta calada (...). Y los hombres con el guante blanco y la expresión donde la inconsciencia clama venganza dispararon y el ejército disparó y la gente caía pesadamente, moría y volvía a caer, se escondía en sus aullidos y se resquebrajaba, seguía precipitándose hacia el suelo como una sola larga embestida interminable, sin tocarlo nunca, sin confundirse jamás con esas piedras (...). Los fusiles y los revólveres y las ametralladoras entonaban un canto sin claudicaciones a lo que moría, a lo que concluía entonces, iluminando con denuedo, con hostil premura, por la luz de bengala que había lanzado un helicóptero. ${ }^{3}$

3 MONSIVÁIS, Carlos. Días de guardar, 1988, pp. 302-303. 
Durante los agitados días de 1968, en las páginas de Excélsior era posible advertir la independencia informativa que su nuevo director procuraba, no sin resentir frecuentes presiones: "No ocultábamos las noticias. Tampoco la magnitud del fenómeno. En aumento incesante nuestras ediciones consignaban desplegados de todos tamaños en apoyo al movimiento estudiantil. Aumentaba también el número de telefonemas a mi oficina que recomendaban prudencia". 4 (Scherer, 1986: 21).

La política informativa asumida en Excélsior con la llegada de Julio Scherer, pronto empezó a resultar incómoda al presidente Gustavo Díaz Ordaz (1964-1970), quien no precisamente se distinguía por su apertura y tolerancia. En 1969, Jorge Saldaña, el conductor de la serie de televisión Anatomías, dedicó una edición de su programa al tema Excélsior. Para desacreditar el trabajo de Scherer, Saldaña invitó a algunos de los trabajadores que fueron expulsados del diario en 1965, quienes describieron su antigua casa editorial como "un antro". Jorge Velasco, quien se desempeñó como secretario del Consejo de Vigilancia en Excélsior, depuesto en 1965, reveló años después a Julio Scherer la intervención de Luis Echeverría Álvarez, titular de la Secretaría de Goberna- ción durante el gobierno de Gustavo Díaz Ordaz, en la campaña de difamación contra Excélsior. Echeverría desvió dinero del erario público para financiar las actividades de los trabajadores expulsados de Excélsior en 1965. El secretario de Gobernación del presidente Gustavo Díaz Ordaz financió desde la renta mensual del local que alquilaron los conspiradores en el edificio San Antonio, en avenida Juárez 68 en el Centro Histórico de la Ciudad de México, hasta las percepciones mensuales, gastos para cubrir enfermedades, vacaciones, gratificaciones trimestrales y aguinaldo. En 1969, en el penúltimo año de gobierno del presidente Díaz Ordaz, la campaña contra Julio Scherer y Excélsior se extendió a otros medios: "Fue insólito el titular de El Día, a ocho columnas, el 25 de agosto, remate de una campaña de difamación y desprestigio: 'Miente Excélsior'. Excélsior era tendencioso, amarillista, vendido a causas deleznables. Multiplicados sus disfraces, aparecía el poder por todos lados". 5

El primero de diciembre de 1970, Luis Echeverría Álvarez asumió la presidencia de los Estados Unidos Mexicanos. Como candidato a la presidencia de la república por el Partido Revolucionario Institucional (PRI), Echeverría rompió todos los récords

4 SCHERER, Julio. Estos años, 1986, p. 21.

5 Ibídem, p, 28. 
establecidos en campañas presidenciales al recorrer 56.150 kilómetros, pronunciar cientos de discursos y realizar miles de promesas. De acuerdo con el destacado historiador Enrique Krauze, el presidente Echeverría se propuso introducir un cambio radical en el rumbo histórico del país:

Desde un principio Echeverría se propuso introducir un cambio radical en el rumbo histórico del país. Nuevo Cárdenas volvería a los orígenes nacionalistas, campesinos, justicieros de la Revolución (los suyos propios en la juventud); pero al mismo tiempo les infundiría el nuevo contenido ideológico que desde los años sesenta habían formulado sus coetáneos intelectuales de izquierda, los maestros universitarios que integraban aquella generación de Medio Siglo educada en el marxismo académico francés. Echeverría subrayaba su filiación al grupo, hablaba de "esta generación en cuyo nombre hemos llegado a la presidencia" (...). Con los maestros universitarios pertenecientes a su propia generación, la operación integradora fue sencilla. Muchos de ellos - Horacio Flores de la Peña, Porfirio Muñoz Ledo, Víctor Flores Olea, Enrique González Pedrero, entre varios otros - se incorporarían a su gabinete o tendrían puestos importantes en empresas $\mathrm{u}$ organismos del sector público. Otros serían sus asesores y estarían permanentemente a sueldo (Ricardo Garibay, aquel escritor pagado por Díaz Ordaz que conocía a Echeverría desde tiempos inmemoriales, recibía, según su propia confesión, 80 mil pesos o 6.500 dólares al mes) (...). El más famoso de los miembros de la generación, el escritor Carlos Fuentes, se convirtió desde mediados de 1971 en un ideólogo y defensor activo del régimen echeverrista, y en 1975 aceptó la embajada en París. ${ }^{6}$

Entre tanto, Julio Scherer afirmaba la independencia informativa de Excélsior:

El grupo de Scherer atraviesa por estos círculos del cinismo y la corrupción y de modo paulatino intuye, inicia y propone un periodismo distinto. No hablo de milagros sino de espacios arrebatados a las inercias del miedo y la deshonestidad. Y si 1968 es al momento del salto mental, el sexenio de Luis Echeverría, educa en la eliminación del autoengaño. Echeverría cree desproporcionadamente en la imagen que obtendrá de los Medios, en especial de la prensa, y por eso recompensa la largueza a los reporteros, negocia con los dueños de las empresas periodísticas, arrastra consigo a cientos de reporteros que cantan sus alabanzas (en lo posible, que nunca es mucho) y reafirman su dimensión de estadista internacional.

6 KRAUZE, Enrique. La presidencia imperial. Ascenso y caída del sistema político mexicano (19401996), 1997, p. 370. 
Pero la torpeza, la ineptitud, la corrupción que se vislumbra y los ecos sordos de la represión hacen que Scherer y su grupo cercano ejerzan ya el distanciamiento.

Entonces las alusiones desfavorables hacen el papel de críticas frontales, y así el historiador aficionado Gastón García Cantú pasa por oposicionista acérrimo. A Echeverría, educado en la unanimidad ("La República sólo conoce un sonido: la voz presidencial"), las críticas le irritan o le indignan (¿cómo advertir los matices de un burócrata exaltado?), y por eso se dispone al aplastamiento de los periodistas herejes. Al principio Scherer no lo cree por una razón elemental: ante el poder presidencial Excélsior es tan poca cosa que no hace falta una conspiración para quitar de su sitio al director. Pero Echeverría está convencido de su dualidad: el político antiguo con el repertorio de traiciones y bajezas, y el estadista moderno que recibe a la emigración chilena, que protege al Tercer Mundo, que habla como si entendiera a Frantz Fanon y a Paulo Freire. Y mientras quiere resolver de una plumada el conflicto árabe-israelí, prepara la caída del insolente y los suyos. ${ }^{7}$

El presidente Luis Echeverría no perdía oportunidad para pregonar la libertad de expresión que había alcanzado la prensa durante su gobierno. Sin embargo, la realidad era muy dife-

7 MONSIVÁIS, Carlos. Op. cit., 2006, p. 22.

8 SCHERER, Julio. Op. cit., 1986, p. 76. rente. En 1972 el presidente Echeverría instigó un boicot publicitario contra Excélsior entre acaudalados empresarios e industriales del Comité Coordinador Empresarial. A pesar del impacto del boicot empresarial en las finanzas del diario, Excélsior no modificó su política editorial. Julio Scherer había convertido a Excélsior en el principal diario en México:

No inmortaliza la palabra presidencial ni cambia la naturaleza el soplo de su aliento. Sin embargo, habíamos dedicado al presidente los encabezados de nuestra primera plana con monótona regularidad. Abandonamos la costumbre. Más y más descendían al centro de la página frontal del diario y aun a sus páginas interiores los discursos de Echeverría. Pasaba a mejor vida la sección de sociales, catálogo de matrimonios, fiestas, modas, bautizos, confirmaciones, banquetes. Desaparecía el Día de las Madres con el mensaje del Papa a las cabecitas blancas y el festejo del 10 de mayo en el Auditorio Nacional, el director del periódico a un lado de la primera dama, cortesano obligado. Crecía el número de reporteros que se hacían de un prestigio propio, enriquecíamos la información internacional con servicios en todo el mundo. Las páginas editoriales eran cabalmente independientes y en la sección deportiva se hablaba de los ratoncitos verdes en pos de gloria. ${ }^{8}$ 
El presidente Echeverría enseguida impulsó una campaña de calumnias y difamaciones contra Excélsior. Bajo la pluma apócrifa de un tal José Luis Franco Guerrero, circuló un cuadernillo quincenal titulado Las malévolas noticias de Excélsior. Además, sin pie de imprenta circuló El Excélsior de Scherer, firmado por Efrén Aguirre. La campaña difamatoria también se extendió a algunos intelectuales independientes que resultaban incómodos al gobierno de Luis Echeverría, como Daniel Cosío Villegas, editorialista de Excélsior.

El primero de septiembre de 1973, Echeverría hizo una referencia despectiva a los 'solitarios de gabinete' que por 'ganarse un salario' y frente a una maquinilla de escribir formulaban 'sin reflexión cualquier crítica que se traduce (...) en denuesto'. Sintiéndose aludido, Cosío Villegas, defendió desde su tribuna editorial el derecho de un escritor de disentir del poder. A principios de 1974 comenzó a circular profusamente un libelo de autor anónimo que difamaba a Cosío Villegas bajo el título de Danny, discípulo del Tío Sam. En él se le pintaba como un vividor, explotador de braceros, cronista de burdeles parisinos, comunista convencido y -desafiando la lógica - servidor a sueldo de los norteamericanos. ${ }^{9}$

En el verano de 1976, durante el último año de gobierno del presiden- te Luis Echeverría, el peso sufrió una severa devaluación frente al dólar. De 12 pesos y 50 centavos por dólar estadounidense, la nueva paridad fue establecida en 70 pesos por dólar. El hecho fue motivo de festejo en la Cámara de Diputados, controlada entonces por el PRI.

El licenciado José López Portillo, secretario de Hacienda y Crédito Público durante el gobierno de Luis Echeverría, por voluntad de este fue "destapado" el 22 de septiembre de 1975 como candidato presidencial del PRI en los comicios presidenciales de 1976. A la candidatura de López Portillo se sumaron dos partidos políticos de los cuatro que entonces contaban con registro. Así, López Portillo fue candidato presidencial de tres de los cuatro partidos que entonces contaban con registro: el Partido Revolucionario Institucional (PRI), el Partido Auténtico de la Revolución Mexicana (PARM) y el Partido Popular Socialista (PPS). El simple sufragio de José López Portillo hubiese sido suficiente para definir la elección presidencial de 1976. El Partido Acción Nacional (PAN) -el cuarto partido político con registro- optó por no presentar candidato a la Presidencia de la República en los comicios de 1976.

Poco antes de las elecciones presidenciales de 1976, el presidente Luis Echeverría decidió asestar el golpe

9 KRAUZE, Enrique. Op. cit., 377. 
definitivo contra la directiva de Excélsior. El 10 de junio de 1976, Humberto Serrano, "líder agrarista" y diputado federal del PRI, "movilizó" a un grupo de campesinos para invadir los 951.913,39 metros cuadrados de propiedad de la cooperativa de trabajadores del periódico Excélsior, en el fraccionamiento Paseos de Taxqueña, ubicado al sur de la Ciudad de México. Ni la policía ni el Ministerio Público actuaron para impedir la invasión de los terrenos, a pesar de las demandas penales que interpusieron los abogados de Excélsior. Además de promover la invasión a los terrenos ubicados en Paseos de Taxqueña, el presidente Echeverría fraguó la conspiración que en la agitada asamblea de cooperativistas, celebrada el 8 de julio de 1976, desconocería a Julio Scherer como director de Excélsior:

Como antecedente del clima de violencia que se buscaba instaurar, fue impedida la publicación de un comunicado que, bajo la firma de escritores del diario, debía aparecer precisamente ese día. Como anticipo del género de periodismo que a partir de entonces se haría en Excélsior, la página 22 apareció en blanco en vez de contener la advertencia y denuncia de escritores, artistas, funcionarios y periodistas que hicieron de las páginas de Excélsior uno de nuestros espacios críticos fundamentales. "Si la situación de Excélsior se modificara de modo ilegítimo", decían los firmantes, ellos no estarían "dispuestos en forma alguna a continuar (su) colaboración" en ese diario. ${ }^{10}$

Regino Díaz Redondo usurpó el cargo de director general de Excélsior, del 8 de julio de 1976 al 20 de octubre del 2000. Ese día los cooperativistas de Excélsior, en Asamblea General Ordinaria, expulsaron a Regino Díaz Redondo, y el equipo que encabezaba. Fabrizio Mejía Madrid narró en Letras Libres su expulsión:

El 20 de octubre, el periodista espurio por antonomasia, Regino Díaz Redondo, aparece en todos los medios: entre empujones, abandona la asamblea de los cooperativistas del diario Excélsior, farfullando, abismado ante el fin de su propia historia. Lo que me impresiona son sus ojos. Están muertos. Es el Pinochet mexicano que cae cuando se desmorona el apoyo que lo sostiene. No hay nada más obvio que lo que nos sorprende: al perder el PRI, la red de complicidades que movió e hizo hablar a Regino se desconectó y los ojos del títere se nos revelaron como muertos. Y entonces nos damos cuenta: Excélsior fue un cadáver durante 24 años.

La historia que lleva a la salida de Regino del periódico que usurpó en 1976 es tan obvia como picaresca: Excélsior, un diario, es rescatado por el

10 Proceso 1, 6 de noviembre de 1976, p. 14. 
Fobaproa como si se tratara de un banco. Con una deuda de 153 millones, logra reestructurar, con la intervención de la Secretaría de Hacienda, una quita de cuarenta millones (el Subcomité de Recuperación recomendó a Inverlat "no endurecer la posición por lo pronto, hasta tener definida la opinión de la $\mathrm{SHCP}^{\prime \prime}$ ), $\mathrm{y}$, durante tres años, va sorteando con base en relaciones políticas el embargo de los terrenos de Paseos de Taxqueña (los mismos que "justificaron" a los ojos de Jacobo Zabludowsky el golpe a Julio Scherer en 1976), lotes en Tulyehualco, Tequesquitengo, Avenida Chapultepec, la bodega de Vallejo, el edificio de Bucareli y las rotativas. Pero, simultáneamente a la deuda, Regino es acusado de desvíos de fondos por 25 millones desde 1993: las cuentas del diario en Bancomer (514990-1) y Comermex (214643-6) no se encuentran a nombre de "Excélsior Compañía Editorial Sociedad Cooperativa de Responsabilidad Limitada", sino a los de Regino Díaz y Juventino Olivera, quienes se quedan con los intereses, a pesar de que sus sueldos nominales alcanzaban los $75 \mathrm{mil}$ pesos mensuales.

Lo que asombra es la obviedad. A los favores recibidos, Regino responde con los ojos puestos en su benefactor más habitual: un mes antes de la elección presidencial, Excélsior publica la versión de los diputados del PRI de que hay fondos 'externos' en la campaña de Vicente Fox y, tras las elecciones en las que el PRI pierde, Regino publica un editorial más allá de lo vergonzoso:
Excélsior reconoce que su política editorial durante los meses de campaña fue labastidista. Estuvimos convencidos de que era la mejor opción para que se ejecutaran cambios radicales y salir adelante. Nosotros no tenemos grupos de poder económico atrás para sustentar nuestra línea de conducta. Muchos medios sí. Hemos sido siempre y lo seremos el centro de la atención y del ataque artero de los que desde hace un cuarto de siglo han sido nuestros enemigos gratuitos, de los frustrados que salieron del periódico por una decisión mayoritaria de los cooperativistas, de los que llenos de rencores y frustraciones no pierden oportunidad para atacar con deducciones especulativas y deshonestas, con envidia y con anónimos.

Regino presintió una amenaza personal en la derrota del PRI. En la última edición dirigida por él, publicó un desplegado que comenzaba: "La desaparición de Excélsior está programada para hoy". Pero, como siempre, miró mal las cosas. Era su dirección la que estaba en juego. Al mediodía del viernes 20 de octubre, los repartidores, a quienes desde 1995 se les había prohibido llevarse un solo periódico a su casa, abrieron las puertas de Excélsior para que los demás medios filmaran la propuesta de Regino de poner a la venta el periódico. Tres horas después, Regino presidía la asamblea de un periódico al que llamó s.c.r.l. en vez de s.c.l. Comenzó la protesta. Regino dijo que el cambio era por mandato de la Cámara de Diputados, pero los cooperativistas argumentaron que, de acuerdo con el Registro 
Público de la Propiedad, los directivos del periódico habían registrado la nueva cooperativa con una asamblea extraordinaria que no tuvo lugar. Así comenzó la caída. Patricia Guevara fue electa presidenta de la mesa de debates en vez de Regino, quien escapó argumentando que la asamblea era ilegal. En ausencia fue destituido. Subió a su elevador y bajó hasta su Lincoln gris. Nadie lo ha visto desde entonces. ${ }^{11}$

En los días inmediatos al 8 de julio de 1976, el presidente Luis Echeverría, quien entonces promovía su candidatura al Premio Nobel de la Paz, afirmaba su inocencia en la separación de Julio Scherer: "Fue una determinación de los cooperativistas y no ha intervenido el gobierno de México y nunca lo hizo menos al final absolutamente. Parece ser que allí una mayoría determinó lo que hizo después" ${ }^{12}$

A pesar de la violencia distintiva de la "presidencia imperial", algunos medios nacionales e internacionales, abiertamente manifestaron su inconformidad por el golpe de Estado cometido por el presidente Luis Echeverría contra la directiva de Excélsior:

Contrastando con el silencio casi total de la prensa diaria capitalina y de la televisión comercial, que callaron una vez cumplida su labor, semanarios como la revista Siempre y un buen número de diarios de provincia informaron de lo acontecido y enjuiciaron severamente el golpe contra Excélsior. También lo hizo la prensa mundial, encabezada por sus órganos más significativos, tales como The New York Times, The Washington Post, Le Monde, The Times, The Manchester, The Guardian de Inglaterra, etc.

En la edición del 28 de julio de 1976 de la revista Siempre, destacados intelectuales reprobaron el golpe asestado a Excélsior. Entre los intelectuales que públicamente expresaron solidaridad hacia Julio Scherer destacaban Octavio Paz, Gabriel Zaid, Juan García Ponce, Alejandro Rossi, Salvador Elizondo, José de la Colina, Tomás Segovia, Ramón Xirau, Jaime García Terres, Luis Villoro, José Emilio Pacheco, Gastón García Cantú, Enrique Krauze, Manuel Felguerez y Elena Poniatowska. Renato Leduc y Antonio Caram, directivos de la Unión de Periodistas Democráticos, también manifestaron su repudio al golpe contra Excélsior.

Diez días después del golpe a Excélsior, más de dos mil personas acudieron a la reunión de la que derivaría un nuevo proyecto editorial encabezado por Julio Scherer: el

11 MEJÍA MADRID, Fabrizio. "Regino y Excélsior". Letras Libres [en línea]. En $<$ http://www.letraslibres.com/index.php?art=6630>. [Consulta: 28 de marzo del 2007].

12 SCHERER, Julio. Op. cit., 1986, p. 214. 
semanario Proceso. A pesar de intimidaciones de Mario Moya Palencia, secretario de Gobernación, y gracias al editor Guillermo Mendizábal, quien tenía un espantoso taller en la calle de José María Rico, el primer número de Proceso empezó a circular en la Ciudad de México el sábado 6 de noviembre de 1976, veintiséis días antes de concluir el gobierno del presidente Luis Echeverría. La editorial del primer número de Proceso resultó un contundente revés para el aún presidente:

A la condición azarosa de todo proyecto humano se añaden, el caso de este semanario, que hoy inicia su presencia en la vida pública mexicana, modalidades que le confieren una peculiar naturaleza. Esta publicación surge, entre dificultades remontadas penosamente, al calor de la lucha por la libertad de expresión, lucha perenne entre la prensa que busca ser responsable y el poder que no se ciñe a la legitimidad.

Este semanario nace de la contradicción entre el afán de someter a los escritores públicos y la decisión de éstos de ejercer su libertad, su dignidad. Estas prendas valen en tanto posibiliten el que a través de ellas se expresen los que no pueden hacerlo de otro modo. Como bien lo han entendido quienes de varias emocionantes maneras contribuyeron a su aparición, Proceso no sirve sólo al propósito -que en sí mismo resultaría menor- de dar voz a un grupo de trabajadores del periodismo. La tarea real de Proceso trasciende a los periodistas que lo hacen, en la medida en que asuman su compromiso con su tiempo y con su país.

En sí mismo, Proceso es un acto de confianza en la capacidad de nuestra sociedad para madurar como nación. Agobiados por signos en contrario, lo peor que puede ocurrir a los mexicanos es desesperar de las posibilidades democráticas de remontar la crisis que hoy nos abruma. Con la ruindad que es propia del anónimo, surcan hoy el país toda clase de adjetivaciones contra el régimen. Con el solo hecho de proclamar su nombre y el de sus autores, Proceso ejercerá su actividad crítica sin sumarse a tal desahogo. Por lo demás, sería un ínfimo propósito el aparecer sólo para combatir a un gobierno que vive sus últimas horas.

En medio de señales ominosas, entre las cuales la información y la crítica pública pudieran aparecer exóticas o peligrosas, Proceso asume el compromiso de brindarlas. Nos empeñamos en hacerlo porque estamos persuadidos de que es importante contribuir a que la nación se conozca a sí misma para que a partir de su propia conciencia pueda delinear su porvenir justo y libre.

Testigo del transcurrir social, del proceso inacabable de los hechos con que el hombre edifica su historia, este semanario aspira a no ser relator de los acontecimientos, simple correa transmisora entre la realidad y los lectores. Puesto que el hacer humano tiene sentido, se requiere también un proceso analítico para determinar si 
tal afán sirve o no para mejorar a los hombres y a las comunidades que ellos integran.

Proceso de los hechos, proceso a los hechos y a sus protagonistas: estas son las líneas de acción de nuestro semanario. Golpeados por la inquina política en términos que causaron asombro dentro y fuera de México, por la impudicia de la agresión y la relevancia de quienes lo concibieron, sus miembros no harán de Proceso un semanario del despecho y el resentimiento. Primero, porque comprenden la naturaleza política de los hechos en que se les ha involucrado. Y en segundo lugar, y sobre todo, porque los conforta y obliga la solidaridad y generosidad de un vasto número de mexicanos decididos a que el silencio no cubra por completo a esta nación. ${ }^{13}$

El 6 de noviembre de 1996, al cumplir Proceso 20 años de vida, en la página tres de la edición 1044, Julio Scherer, Vicente Leñero y Enrique Maza anunciaron su salida para dar lugar a un relevo generacional. Un consejo editorial, integrado en su mayoría por miembros fundadores (Rafael Rodríguez Castañeda, Froylán M. López Narváez, Carlos Marín, Francisco Ortiz Pinchetti, Carlos Puig y Gerardo Galarza), asumió la dirección de la revista. Diez años después, Rafael Rodríguez Castañeda se desempeña como director de Proceso.
No sin algunas diferencias decidieron abandonar Proceso Froylán López Narváez, Carlos Marín, Francisco Ortiz Pinchetti, Carlos Puig y Gerardo Galarza.

Entre el 6 de noviembre de 1976 y el domingo 25 de marzo del 2007, 1.586 ediciones de Proceso han sido publicadas. La comprensión de la historia del periodismo independiente en México no sería posible sin la contribución, definitiva, del semanario Proceso. De la edición especial del aniversario treinta de Proceso, recuperamos las palabras de Enrique Semo:

Proceso es una publicación que ha hecho historia. Los tiempos han cambiado y la prensa también, pero, a su manera, ha hecho historia. Informando lo que los poderes callan, influyendo en la opinión pública, abriendo caminos para el pensamiento crítico y condicionando a cada paso el quehacer político, durante 30 años. Proceso nació de un atentado contra la libertad de expresión. El golpe de Estado público que orquestó Luis Echeverría contra el diario Excélsior en su último año de gobierno, expulsó al grupo de periodistas que habían hecho de ese periódico el más respetado de México. Con el apoyo de un grupo de intelectuales y profesionistas, ellos decidieron no rendirse, volver a la

13 Proceso 1, 6 de noviembre de 1976, p. 5. 
carga, abrir un espacio para continuar la labor iniciada. Así surgió Proceso y así ha continuado, de prueba en prueba, de presidente en presidente, sin conceder y sin desesperar hasta hoy. En 2006, vuelve a estar donde estuvo en 1976: presionado, reprobado en los medios de la buena sociedad y demandado legalmente ante el Poder Judicial, esta vez por la familia presidencial. Una familia que se va, como se fue en su hora López Portillo, que también decidió agredir a Proceso en su último año de gobierno, en medio del desastre, del naufragio, incluso el ridículo.

\section{La democratización de los medios electrónicos}

La semana del 26 de abril del 2007 ya es historia, por el lanzamiento de un nuevo dispositivo que va a marcar los siguientes diez años del mundo de la comunicación: Apple TV. Por aproximadamente 180 dólares, este nuevo dispositivo permitirá interfasear internet con la televisión. Hasta el día de hoy, básicamente veíamos televisión o chateábamos en internet, pero este nuevo dispositivo (con opción a wireless), trae a la televisión todo lo que hay en internet, sobre todo los videos, lo más complicado de interfasear.
Esta nueva tecnología implica un impresionante cambio cualitativo en los medios, ya que en cada uno de nosotros hay potencialmente una televisora. Cualquier contenido que produzcamos en internet y subamos a la red, podrá convertirse en un programa de televisión. Por ello, aquellas personas que creen contenidos en internet tendrán su propia estación de televisión.

Además, en los próximos meses, aparecerá otro dispositivo que también va a modificar la forma de cómo pensamos y concebimos la comunicación. En junio del 2007, saldrá al mercado el iphone: teléfono, ipod y geoposicionador y, lo más novedoso, acceso abierto a la red (audio, video, podcasting) en dispositivo móvil wireless con alta potencia. Todo en uno. Es una gran revolución por la movilidad absoluta de la red, sin tener que transportar una computadora.

En el mismo año tenemos la democratización de los medios electrónicos y la movilidad total de la web. ¿Somos conscientes de la manera en que va a cambiar nuestra manera de comunicarnos y de nuestro acceso a la información? El índice de penetración de internet va a subir espectacularmente, porque todas las personas que hoy día tienen un celular, ${ }^{14}$ por lo menos en un porcentaje elevado van a

14 La venta de celulares en el mundo creció un 21,3\% durante el 2006, con 990,8 millones de unidades vendidas, según la consultora Gartner. Véase La Jornada, 21 de marzo del 2007. 
adquirir este dispositivo. Y para aquellos a quienes no les resulte asequible, próximamente podrán adquirir una computadora por cien dólares ${ }^{15}$ en cualquier establecimiento, a finales del 2007, en México.

Además, el lector no solo no se ve reflejado en los medios, sino que la información que para él resulta más relevante la encuentra en internet, en ipods y en blogs, creando sus propias redes de información, de opinión y de entendimiento, convirtiéndose en un usuario intensivo de estos nuevos medios.

El capital ya no es lo más importante para crear un nuevo medio. Cualquier persona con pocos recursos, pero con una idea inteligente, puede hacer un gran medio. Myspace, Youtube, Google son el ejemplo de jóvenes con grandes ideas en el contexto de los nuevos medios.

\section{El principio del verdadero ciberperiodismo en México: Reporte Índigo}

En la agonía del decepcionante gobierno del presidente Vicente Fox Quezada, el viernes 27 de octubre admite ser considerado como auténtico parteaguas en la historia del periodismo en el México contemporáneo. Ese día la respetada periodista Carmen Aristegui, titular del noticiero radiofónico Hoy por hoy, entrevistó al destacado periodista regiomontano Ramón Alberto Garza, egresado de la primera generación de la licenciatura en ciencias de la comunicación del Tecnológico de Monterrey, Campus Monterrey, quien dio a conocer Reporte Índigo, inteligente proyecto de investigación periodística en avanzado formato multimedia y digital.

Ante un escenario donde los grandes periódicos de todo el mundo no reportan aumento de lectores ni de publicidad, y donde cada vez se sintoniza menos la televisión abierta, surgió a finales del año pasado la primera experiencia digital multimedia creada en el mundo. No hay un concepto igual hasta el día de hoy como Reporte Índigo, tal y como explica su creador:

La información es de todos. Está en todos lados. En exceso. Y paradójicamente, es este exceso lo que nos confunde. Nos llena de ruido. Para el conocimiento, un buen contenido es

<http://www.jornada.unam.mx/ultimas/2007/03/21/crece-21-3-el-numero-de-celularesvendidos-a-nivel-mundial-en-2006>. [Consulta: 29 de marzo del 2007.]

15 Siguiendo el ejemplo del proyecto de Nicholas Negroponte y la empresa sin fines de lucro One Laptop per Child (OLPC) [en línea], creada con el objetivo de llevar la alfabetización digital a cada escuela del mundo, mediante el uso de una laptop de 100 dólares, rompiendo todos los esquemas sobre la alfabetización digital. <http://laptop.org/index. es.html>. 
necesario, pero no suficiente. Los medios nos dicen pasó esto o aquello, pero rara vez nos dicen por qué. Y es esta pregunta la que nos lleva al verdadero entendimiento de nuestro entorno. Rescatemos la intuición como elemento fundamental del conocimiento. Elaboremos hipótesis. Hagamos conexiones. Creemos conciencia y hagamos un cambio... juntos. ${ }^{16}$

Ramón Alberto Garza García ha desempeñado importantes cargos en algunos de los principales diarios nacionales. Entre 1994 y 2000 se desempeñó como director editorial de Reforma y El Norte. En el 2000, no pocos periodistas e investigadores especulaban sobre las posibilidades de desarrollo de Ramón Alberto Garza como profesional de la comunicación del llamado "gobierno del cambio". Sin embargo, ese año, Garza optó por incorporarse a Esmas.com y Editorial Televisa. Entre los principales proyectos editoriales en los cuales participó destaca la revista Cambio, efímera versión mexicana del prestigioso semanario de información, editado en Bogotá, Colombia, ${ }^{17}$ fundado en 1993 como Cambio16, del cual Gabriel García Márquez es presidente del consejo editorial.
Inesperadamente Garza pasó a El Universal, donde laboró hasta el 17 de diciembre de 2002. Entre los episodios delicados que enfrentó Ramón Alberto Garza como director y vicepresidente ejecutivo del "gran diario de México", destaca el despido del columnista Francisco Rodríguez. Ramón Alberto Garza es de los pocos periodistas en México efectivamente conocedores de la importancia que admiten las avanzadas tecnologías de información en la titubeante construcción del nuevo periodismo.

La gestión de la información periodística, como la gestión de la información en general, puede ser analizada a través del Modelo de Rowley, ${ }^{18}$ y comprende cuatro grandes dimensiones de análisis: entorno de la información, contexto de la información, sistemas de información, interfases persona-información.

En la primera entrega de Reporte Índigo destacó la primicia del libro Fin de fiesta en Los Pinos, de la periodista Anabel Hernández, quien, de acuerdo con el propio Garza, "hace revelaciones muy fuertes de lo que son las nuevas situaciones de la familia Fox. Entre otras cosas, habla de presuntas vinculaciones y protecciones al nar-

16 Véase Reporte Índigo en <http://www.reporteindigo.com>.

$17<$ http://www.cambio.com.co $>$.

18 CORNELLA, Alfonso. Infomanía.com. La gestión inteligente de la gestión en las organizaciones, 2002, pp. 102-103. 
Imagen 1. Por medio de un sistema "push", Reporte Índigo es distribuido semanalmente a las cuentas de correo electrónico de los suscriptores. Por ahora, la suscripción es gratuita.

cotráfico por parte de familiares, en particular de la primera dama... concreto al 'Chapo' Guzmán”. Se habla ampliamente en estos capítulos sobre las dudas de la muerte de Ramón Martín Huerta, sobre quién habría sido la mano que estaría detrás del accidente de ese funcionario, $\mathrm{y}$ también vienen por ahí unos capítulos muy importantes sobre las concesiones para operar una línea aérea llamada A Volar, entregadas a José Alberto Bribiesca y a su tío Guillermo Sahagún, otorgadas por la SCT, y muchas cosas más.

\section{Claves del éxito de Experiencia Índigo}

La información se volvió un commodity. Todos tenemos acceso a la información gracias a internet, y ahora la gente no está dispuesta a pagar por algo que está en la red. Los lectores y televidentes solo están dispuestos a pagar por dos cosas: primero, el entretenimiento. El lector debe sentirse provocado. Un ejemplo del éxito de la industria del entretenimiento es la del videojuego. En segundo lugar, el entendimiento, ya que ante la gran 
oferta de información, el lector lee pero no entiende. Se hace imprescindible proporcionar al lector las claves para entender acontecimientos futuros. Por último, hoy en día, la gente no busca ni bienes ni servicios, sino experiencias diferentes.

Los tres elementos (entendimiento, entretenimiento y experiencia) resultan imprescindibles para crear un nuevo medio de comunicación. Audio, video y broadcasting en Reporte Índigo relatan la misma historia que los medios tradicionales, pero de una manera poco convencional.

Confiamos que las aportaciones y los puntos de vista que encontrarás en estas páginas, servirán para interpretar mejor tu entorno. Esperamos provocar nuevas visiones y enfoques de la realidad. Y lograr un diálogo constructivo para mejorar.

Creemos que no hay transformación sin participación. No hay participación sin conciencia. Y no hay conciencia sin entendimiento. Exploremos juntos la política, la economía y la sociedad de México y de otros países. Vayamos más allá de los hechos. Leamos entre líneas. Aprendamos del pasado. Conozcamos los porqués. ${ }^{19}$

Reporte Índigo nació curiosamente la misma semana (septiembre del 2006) en la que apareció en la portada de The Economist "Who killed the newspaper?", portada que conmocionó la industria de las comunicaciones, ya que un diario tan influyente como este formalizaba el nuevo escenario de los medios. Según el artículo de The Economist, el último periódico tirado a la basura se dará allá por el año 2043. Pensar qué va a ocurrir en el futuro, enfrentarlo y operacionalizarlo en el presente, es lo que ha hecho Ramón Alberto Garza y su equipo, formado por 36 personas.

La apuesta de Reporte Índigo se basó en primer lugar en pensar quiénes son y serán su público: la generación net. Somos conscientes de que estamos en la actualidad ante la primera generación digital verdadera, que no piensa de manera lineal, sino en bloques, en imágenes, en multiniveles. Esto supone un nuevo modelo de pensamiento en un contexto mediático complejo. Reporte Índigo aprovecha una convergencia real, explotando la convergencia digital de la radio y la televisión con un bajísimo coste de distribución, para presentar una oferta metamedia, que se concreta en su editorial digital.

La oportunidad de Reporte Índigo está en la innovación, creando contenidos provocadores, con una nueva arquitectura informativa y organizacional. No hay en su redacción editores ni redactores ni reporteros sino provocadores, catalizadores y contex-

19 Véase Reporte Índigo <http://www.reporteindigo.com>. 
tualizadores de la información que apelan a la gente pensante. Reporte Índigo es, tal y como lo define su creador, Ramón Alberto Garza, un brainmedia, un medio que apela a pensar de una manera crítica.

Además del Reporte Índigo con temas de política, economía, internacional y deportes, también se publica Piensa Índigo, con temas de pensamiento y espiritualidad. Desde el número uno, se elaboró una portada no estática, móvil, que para los más nostálgicos retoma el pasar de las páginas, pero que a la vez emplea el multimedia para hacer más amena la lectura.

Provocar y pensar para mejorar. De todo y de todos tenemos algo que aprender. Del intelectual y del vecino de al lado. Porque el aprendizaje que transforma a veces llega de la mente y

Imágenes 2 y 3 . Experiencia Índigo se nutre de Reporte Índigo y Piensa Índigo, dos publicaciones que reúnen una atractiva combinación: los contenidos críticos y el multimedia. 
a veces del corazón. En ocasiones la vida puede ser densa y en otras, ligera. Todo es cuestión del ánimo con que la vivimos y la interpretamos. Así queremos ser en Piensa Índigo... como la vida. Sorpresiva, impredecible. No apta para aburridos. ¡Disfrútalo!

Reporte Índigo $<$ http://wwwreporteindigo.com>.

Piensa Índigo no pretende ofrecer información sino puntos clave sobre temas de reflexión, con colaboracio- nes de expertos. La novedad radica en su presentación: divertida, inteligente, amena, con imágenes, música... En definitiva, de una manera provocadora.

Esta Experiencia Índigo ha evolucionado, incorporando un nuevo concepto a sus publicaciones. Se trata del narrador o explicador de la noticia, que aparece visualmente en la página, sustituyendo parcialmente el texto (véanse imágenes 4 y 5).

Imagen 4. En este reportaje, un analista financiero, Carlos Hermosillo, anuncia las claves para entender la economía de México y sus perspectivas de inversión para el 2007.

Imagen 5. El analista financiero explica cada una de las cinco claves en un video. Es como ver la sección financiera de un noticiero de televisión. 
En Reporte Índigo son válidos desde una noticia reporteada como en televisión, por la reconocida periodista Fernanda Tapia, quien introduce su reportaje con un video (imagen 6), hasta el visionado de un tráiler de una película por estrenar junto con fotografías, como el filme de Oliver Stone Las Torres Gemelas (imagen 7).

La bandera de la innovación y la tecnología en Reporte Índigo se materializa en las descargas gratuitas de sus videos a los ipods, en la venta de los boletos de cine y hasta un improvisado karaoke en uno de sus artículos dedicado a los Beatles.

La inversión económica que requiere Reporte Índigo para sostener semanalmente esta propuesta parte de un financiamiento de inversionistas públicos cien por ciento mexicanos. Varios medios de comunicación extranjeros se han puesto en contacto con Ramón Alberto Garza para buscar la franquicia.

Imágenes 6 y 7. 
La publicidad es vital para cualquier medio de comunicación masivo, y también lo es para los nuevos medios. En el primer número de la revista Proceso, la segunda de forros, ${ }^{20}$ en color, fue comprada por Brandy Viejo Vergel. La tercera de forros por La Baguette y la cuarta de forros por el Whisky JB. En las páginas interiores se anunciaron Volkswagen, Seguros La Comercial, La Medalla del Amor Verdadero, Whisky Pinch, Centro de Estudios Históricos del Movimiento Obrero Mexicano (Cehismo), Vuelta, Siglo XXI Editores, Fondo de Cultura Económica, Diálogo en el infierno entre Maquiavelo y Montesquieu. En cambio, las 29 ediciones de Reporte Índigo no registran publicidad. Ramón Alberto Garza es un excelente periodista. Reporte Índigo representa un estupendo proyecto periodístico y seguramente atraerá importantes anunciantes.

\section{Conclusiones}

Proceso admite ser considerado como parteaguas definitivo en la historia de la libertad de expresión en el México contemporáneo. Las páginas de Proceso, perfecto ejemplo de riguroso periodismo de investigación, han consignado las acciones y los hechos más significativos que se han registrado en México en los 31 años recientes. Proceso además ha contribuido a asegurar el efectivo acceso ciudadano a información de interés público. Proceso se ha convertido en una referencia informativa indispensable. En años recientes, sin embargo, como la mayoría de diarios y revistas, Proceso ha empezado a perder lectores. Para comprender el acontecer nacional, Proceso sigue resultando insustituible. En cambio, la información disponible hoy en internet ha restado importancia a otras secciones, la internacional por ejemplo.

Reporte Índigo es una experiencia multimedia digital, la primera posibilidad de integrar la letra, el video y el audio para hacer periodismo. Hay que comprender que no pretende competir con los periódicos, sino complementarlos explicando qué hay detrás de las cosas y a la vez proporcionando entretenimiento.

Reporte Índigo supone un ejercicio libre de comunicación, novedoso y dinámico, para aquellos que a través de la red acceden a información, análisis y a posibilidades muy amplias de entendimiento.

Si bien Reporte Índigo se distingue por el inteligente empleo de avanzadas tecnologías multimedia, su trascendencia periodística no dependerá de la tecnología. Su trascendencia definitivamente dependerá del contenido. Reporte Índigo tendrá que crear su propia historia. Para ello es indis-

20 En México, los términos 'segunda de forros' y 'tercera de forros' equivalen a lo que en el Perú se conoce como 'retira de portada' y 'retira de contraportada'. (Nota de edición.) 
pensable practicar un periodismo crítico y de investigación, sin ningún tipo de concesiones. Reporte Índigo responde a las nuevas exigencias informativas de aquellas generaciones que conciben internet como un medio de comunicación "nativo", no como una nueva tecnología.

\section{Bibliografía}

CORNELLA, Alfons. Infonomía!com. La gestión inteligente de la gestión en las organizaciones. Barcelona: Ediciones Deusto, 2002.

HACES, Cosme. Blog en <http:// deperiodistas.blogspot.com/2006/ 10/reporte-indigo.html>. [Consulta: 30 de marzo del 2007.]
KRAUZE, Enrique. La presidencia imperial. Ascenso y caída del sistema político mexicano (1940-1996). México: Tusquets Editores, 1997.

MONSIVÁIS, Carlos. "Adiós a las concesiones". Proceso. 30 años. Octubre-diciembre del 2006.

—. Días de guardar. México: Era, 1988.

PAZ, Octavio. Posdata. México: Siglo Veintiuno Editores, 1987.

SCHERER, Julio. Estos años. México: Editorial Océano, 1995.

—. Los presidentes. México: Editorial Grijalbo, 1986. 